\title{
Das ölfreie „Herz der Praxis“ wird 50 - Mitfeiern lohnt sich
}

Kraftvoll und ausdauernd stellt der Kompressor als „Herz der Praxis“ dem Praxisteam Druckluft zur Verfügung. In diesem Jahr böte es sich an, damit 50 Kerzen auszublasen. Denn der ölfreie Kompressor feiert Geburtstag - Anlass für ein Gewinnspiel von Dürr Dental für Zahnarztpraxen und Dentallabore in Deutschland und Österreich mit der Aussicht auf einen Duo Tandem Kompressor als Hauptgewinn. Die Preisfrage: Wer hat den ältesten Dürr Dental Kompressor? Und so funktioniert es: einfach Typ, Seriennummer und Bau-

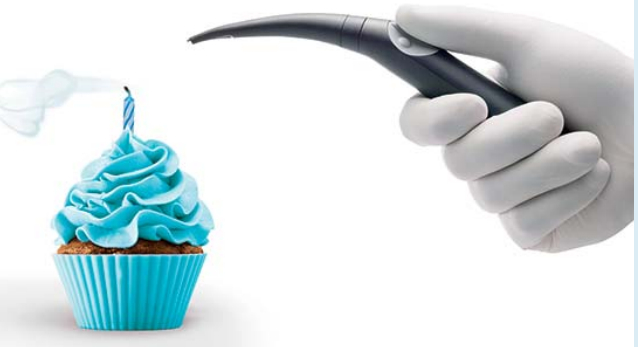

jahr auf der Aktionsseite unter www.duerrdental.com/50jahre eingeben oder auf einer der kommenden Fachmessen die Teilnahmekarten ausfüllen. Wer ein „Herz der Praxis“ der neueren Generation besitzt und am Ende nicht den Hauptpreis erringt, wahrt unabhängig vom Alter des Dürr Dental Kompressors dennoch die Gewinnchance auf eine von 2 Apple Watches, einen von 5 Tischkickern oder eine von 5 Armbanduhren. Die Aktion läuft bis zum 31. Januar 2016.

Den Anlass für diese feierlichen Aktivitäten gibt ein großer Unbekannter: der Kompressor der Praxis. So mancher wird ihn erst suchen müssen, so unauffällig und zuverlässig tut er in der Regel seine Pflicht - und spielt doch eine Hauptrolle. Denn ölfrei, trocken und hygienisch muss dentale Druckluft sein. Ist sie „feucht“, kann sie zum einem zu Korrosion der Luftmotoren an der Behandlungseinheit führen, zum anderen aber auch den Behandlungserfolg gefährden. Feuchtigkeit und Öl im Druckluftsystem begünstigen die Vermehrung schädlicher Keime und beeinträchtigen die Effektivität der adhäsiven Befestigung von Kompositen bzw. Keramik. Darum hat Dürr Dental schon im Jahre 1965 den ersten Kompressor für die Zahnmedizin angeboten, der vollkommen ölfrei Druckluft produzierte. Dank neuartiger, teflonbeschichteter Kolbenringe konnte auf die herkömmliche Ölschmierung verzichtet werden. Heute gleiten die Kolben auf einem speziellen Compound-Werkstoff über die Zylinderlaufbahnen - wie z. B. beim Hauptgewinn Duo Tandem. Dieser kann ohne weiteres seinen Dienst versehen, bis es im Jahre 2040 heißt: 75 Jahre ölfreie Druckluft.

\footnotetext{
Nach einer Pressemitteilung der Dürr Dental AG, Bietigheim-Bissingen www.duerrdental.com
} 